\title{
Un episodio en la recepción del Quijote
}

\author{
Luis Gómez Canseco
}

En 1896 se inició en la Tipografía y Librería Salesianas la publicación del primer tomo de una nueva edición de El ingenioso hidalgo Don Quijote de la Mancha. Los dos siguientes volúmenes, que abarcan la segunda parte, se imprimieron sin cambio en el título en 1897 y todos se presentan como «edición en que se han tenido presentes las mejores publicadas hasta ahora con notas de los comentadores más insignes de esta obra, arreglada para toda clase de personas y en especial para uso de los colegios». Como responsable de la edición aparece don Domingo Abeja.

La «Introducción» abre el primer volumen con una biografía de Cervantes concisa y hagiográfica. Por imperativo de la brevedad o por intención beatificante, su autor determinó prescindir de episodios engorrosos. Ni siquiera la prisión que dio lugar al Quijote merece la más mínima mención. Tras algunas notas inevitables sobre la singularidad del libro, las excelencias de su estilo y la acertada contraposición de caracteres en los personajes de don Quijote y Sancho, tomadas en su mayoría de la Historia de la literatura española de Ticknor, el editor apunta la causa, la intención y el modo de su lectura. En ellos voy a detenerme.

El fin que se propuso Cervantes en el Quijote fue el de exterminar los libros de caballería; no hay que suponer en él una segunda intención, ni filosofía oculta. Cervantes mismo lo afirma repetidas veces que su único propósito fue acabar con la literatura caballeresca; $y$, si hace a las veces una que otra alusión, no le anima ningún móvil mezquino, ni su libro entraña nada simbólico ${ }^{1}$.

Nueve años después de que don Domingo Abeja hiciera esta afirmación categórica. Miguel de Unamuno publicó la Vida de Don Quijote y Sancho, y, unos años más tarde, en 1914, Ortega y Gasset, mirando hacia atrás desde sus Meditaciones del Quijote, escribía:

${ }^{1}$ ABEJA, Domingo: «Introducción», en CERVANTES, Miguel de: El ingenioso hidalgo Don Quijote de la Mancha; tomo I; Sarriá-Barcelona, Tipografía y Librería Salesianas, 1986, págs. 13-14. La casualidad hizo que entre los libros piadosos heredados de un pariente de mi madre, pío y lejano, llegara a mis manos este Quijote igualmente pío. La curiosidad me llevó a repasar las nuevas y sorprendentes aventuras de don Quijote. 
Ha habido una época de la vida española en que no se quería reconocer la profundidad del Quijote. Esta época queda recogida en la historia con el nombre de Restauración (...). Estúdiese la crítica literaria de la época; léase con detención a Menéndez Pelayo, a Valera, y se advertirá esta falta de perspectiva. De buena fe, aquellos hombres aplaudían la mediocridad porque no tuvieron la experiencia de lo profundo (...). El hombre, al ponerse en aguda intimidad consigo mismo, se siente flotar en el universo sin dominio alguno sobre sí mismo ni sobre los demás; se siente dependiendo absolutamente de algo (...), quiero decir, halla una obra, un carácter de quien los límites trascienden por todos lados la órbita de nuestra dominación comprensiva. El síntoma de los valores máximos es la ilimitación.

En estas circunstancias ¿cómo esperar que se pusiera a Cervantes en su lugar? ${ }^{2}$.

¿Qué había ocurrido para que en apenas dieciocho años se produjera un cambio tan considerable? Sencillamente que Unamuno y más tarde Ortega representan a dos generaciones que reaccionaron contra la Restauración, el positivismo y el catolicismo clerical que caracterizaban la segunda mitad del siglo XIX en España. La lectura que del Quijote propone y que, al cabo, impone don Domingo Abeja es la más pura expresión de este siglo, que en 1896 estaba llegando a su fin.

Lo que convierte una obra en clásica es el continuo examen que de ella hacen las generaciones de lectores. Cuando un libro supera ellímite de su estricta contemporaneidad, la quiebra de la circunstancia de su creación y la aparición de nuevas circunstancias de lectura provocan y justifican cambios en su contenido, en su significado. No ha sido el Quijote el libro menos sometido a estas metamorfosis. Probablemente su similitud con la vida real en toda su complejidad ha atraído y luego fascinado a hombres tan separados en el espacio como en el tiempo. Sería interesantísimo disponer de un estudio que nos hablara de las lecturas y los lectores del Quijote, pues no hay poco de cierto en la afirmación de Robert Escarpit: «Saber lo que es un libro es saber cómo ha sido leído» ${ }^{3}$. Este mismo artículo que ahora presento pudiera servir para ilustrar alguna nota del capítulo dedicado al siglo XIX y allí podríamos comprobar que el mayor bagaje que dicho siglo aportó a la comprensión de la obra cervantina fue el de la erudición; la erudición y el juicio moral.

Los estudios literarios decimonónicos -que ahora resultan fuente inapreciable de información- quedaron atrapados en la proximidad de los datos, en la cercanía de lo inmediato. Incluso el Quijote, $\tan$ lleno de referencias al dominio de lo profundo, se vio despojado de toda su perspectiva y su hondura. La explicación, de nuevo en Ortega:

No existe libro alguno cuyo poder de alusiones simbolicas al sentido universal de la vida sea tan grande, $y$, sin embargo, no existe libro alguno en que hallemos menos anticipaciones, menos indicios para su propia interpretación ${ }^{4}$.

\footnotetext{
2 «Meditaciones del Quijote», en Obras Completas; tomo I; Madrid, Alianza Editoria1/Revista de Occidente, 1983, págs. 337-339.

${ }^{3}$ Sociología de la literatura. Barcelona, Edima, 1968, pág. 117.

${ }^{4}$ ORTEGA Y GASSET, J.: op. cit., pág. 360.
} 
El siglo XIX no supo o no quiso ver más allá de las ventas y su preocupación fue saber qué venta real inspiró la literaria y no por qué don Quijote quiso hacer de ésta un castillo. Consecuencia: itinerarios geográficos, identificación de personajes, anotaciones exhaustivas..., erudición. Y juicio moral. Cuando falta la intención de comprender la obra de otros, sobra generalmente la grata costumbre de juzgarla y condenarla según las propias categorías personales o sociales. Los cambios de criterio no han disminuido la afición que todas las generaciones han tenido y tenemos a sentenciar categóricamente.

Durante la Restauración, como durante otras épocas dogmáticas, estos juicios se moralizaron y se hicieron más obvios. De tal modo que el predominio de categorías morales provocó alteraciones, a menudo sorprendentes, en los productos estéticos:

Cuando el libre desarrollo de las artes es regulado por una instancia religiosa o política -escribe Hans Robert Jauss-, el carácter rigorista del canon dominante suele provocar nuevas licencias en el orden de la experiencia estética ${ }^{5}$.

Las licencias que nuestro protagonista, don Domingo Abeja, se tomó en su lectura del Quijote no afectaron sólo a su particular concepto de literatura, sino al del propio Cervantes, a la obra misma y a la lectura que los posibles lectores hicieran de ella. Hasta el punto de poder afirmar que lo que salió de la Tipografía y Librería Salesianas entre 1896 y 1897 no fue el Quijote, no fue, al menos, el Quijote pensado por Cervantes. Los párrafos finales de la «Introducción» pueden advertir de lo que el lector va a encontrarse a partir de las siguientes páginas. La cita, aunque extensa, nos va a resultar imprescindible:

Con más razón dicen otros: «Menester es que este libro se escarde y limpie de algunas bajezas que entre sus grandezas tiene».

Es verdad, «el siglo de Cervantes no era tan delicado. No en obras narrativas tan sólo, hasta en comedias que representaban mucho y habran sido compuestas por sujetos ilustrados y virtuosos, aparecían hechos y se proferían dichos, para nosotros, insoportables». «La decencia, el recato y el comedimiento en el lenguaje no son la moralidad misma, añade Valera, pero son clara muestra del respeto que a la moralidad se tiene (...). El escritor público, ni aun como cita, ni aun para censurar, puede referir ahora los dichos infames y las malas palabras que entonces se usaban sin que los ofdos se ofendiesen y tal vez sin que el rubor asomase a las mejillas de nadie». Esta es la razón que nos ha movido a arreglar la presente edición, expurgada de los pasajes inconvenientes.

Nos hemos esforzado en hacer un trabajo esmerado y concienzudo (...), y nada hemos omitido para procurar sea digno de la buena aceptación del público y de particular ventaja a la juventud ${ }^{6}$.

Después de esto, el lector imagina que las expurgaciones van a limitarse al lenguaje, las expresiones y algunos párrafos breves. No es así. Tras la dedicatoria al duque de Béjar y el prólogo, don Domingo Abeja prescindió de todos los poemas

${ }^{5}$ Expresión estética y hermenéutica literaria. Ensayo en el campo de la experiencia estética, Madrid, Taurus, 1986, pág. 87-88.

${ }^{6}$ ABEJA, Domingo: op. cit.; tomo I; pág. 16-17. 
preliminares. Luego, la lectura de los primeros capítulos viene a confirmar las palabras de la introducción. Hasta el capítulo II, en el que las «dos mujeres, destas que llaman del partido» que encuentra don Quijote en la venta se convierte en sólo «dos mujeres», nada cambia ${ }^{7}$. En adelante, junto a la de algunos juramentos y maldiciones, se descubren tres desapariciones más significativas.

La primera ocurre durante el escrutinio, cuando tras topar entre los libros amontonados en el corral con la Historia del famoso caballero Tirante el Blanco, del comentario que hace el cura se omiten las referencias a la doncella Placerdemivida, la viuda Reposada y los amores ilícitos de la Emperatriz y su escudero Hipólito. En el capítulo VII sólo se echa en falta una línea: «un labrador vecino suyo, hombre de bien -si es que este título se puede dar al que es pobre-». La apostilla, fruto de las entrañas del Miguel de Cervantes real, se elimina en concordancia con la aséptica biografía que lo había presentado en los preliminares de la edición. Por último, del capítulo IX, el de la invención de Cide Hamete, desaparece uno de los mejores ejemplos de la amplificación humorística cervantina: las «doncellas» que edita don Domingo Abeja son simples doncellas, las de Cervantes eran «doncellas, de aquellas que andaban con sus azotes y palafrenes, y con toda su virginidad a cuestas, de monte en monte y de valle en valle, que si nó era que algún follón, o algún villano de hacha y capellina, o algún descomunal gigante las forzaba, doncella hubo en los pasados tiempos que, al cabo de ochenta años, que en todos ellos no durmió un día debajo de tejado, y se fue tan entera a la sepultura como la madre que la había parido» ${ }^{8}$.

Hasta el capítulo XI el expurgo mantiene su criterio y sólo es de destacar el que la canción del pastor Antonio que sirve de epílogo al discurso de la Edad de Oro no aparezca. Sin embargo, cuando el lector avisado, por confiado que fuere en su lectura, se adentra en los siguientes capítulos, comprueba con sorpresa que de Marcela y Grisóstomo no queda rastro. Reduciéndolo a números, han desaparecidos tres capítulos completos: XII, XIII y XIV.

El asombro y la desconfianza aumentan cuando se cotejan los índices del Quijote y del Quijote salido de la Tipografía y Librería Salesianas. La primera parte de aquel tiene cincuenta y dos capítulos que en éste quedan en treinta y cuatro, dieciocho menos. Con la segunda, la censura fue más moderada y sólo se prescindió de seis capítulos, sesenta y ocho frente a los setenta y cuatro originales. El «trabajo esmerado y concienzudo» que anunciaba el señor Abeja en la «Introducción» no se limita a esto, de los capítulos restantes faltan episodios completos, personajes y glosas del autor que obligan a preguntarse si el editor leyó el juicio del bachiller Sansón Carrasco:

Finalmente, la tal historia es del más gustoso y menos perjudicial entretenimiento que hasta agora se haya visto, porque toda ella no se descubre, ni por semejas, una palabra deshonesta ni un pensamiento menos que católico'.

\footnotetext{
${ }^{7}$ Para el cotejo de variantes y expurgaciones he elegido la edición de Juan Bautista Avalle-Arce (Madrid, Alhambra, 1985), que reproduce la edición príncipe del Quijote.

${ }^{8}$ Don Quijote, I, IX.

${ }^{9}$ Don Quijote, II, III.
} 
Realizado el cotejo de variantes y ausencias, puede concluirse que el editor de 1896 censura, arbitraria o sistemáticamente, 1) los episodios idealizantes de amor y fortuna y los de tema pastoril; 2) episodios o elementos cómicos; 3) las expresiones malsonantes; 4) poemas de la primera y segunda parte; y 5) referencias a Dulcinea. El criterio que lo mueve no es en absoluto estético, ni parece que se guíe por la necesidad de abreviar la obra -como sucede en otros Quijotes infantiles o juveniles-, su única intención es moral. El problema consiste en determinar los límites de su moralidad. Para ello debemos empezar por el recuento de las partes censuradas.

Entre éstas, llama la atención la desaparición total de los episodios idealizantes, que hemos dividido en casos de amor y fortuna y de pastores. La afición que el Renacimiento tuvo por los pastores de abolengo platónico se torna perplejidad y escándalo a los ojos del señor Abeja. No son pastores reales los censurables, sino los falsos, los fingidos. Así, no hay entierro de Grisóstomo en el que don Quijote encuentre a Marcela, ni , al final de la primera parte, el cabrero Eugenio cuenta la historia de la bella Leandra y Vicente de la Roca, tampoco contemplan Sancho y su amo el baile alegórico de las serranas en la boda de Camacho el rico, ni topan con la fingida Arcadia en el capítulo LVIII, ni nueve capítulos más tarde proyectan convertirse en los pastores Quijotiz y Pancino.

La culpa es mayor, si cabe, en los episodios de amor y fortuna. Todas las doncellas andariegas, los mancebos enamorados que atraviesan una y otra vez el hilo de la vida de don Quijote y Sancho se desvanecen. Las aventuras de Cardenio, Dorotea, don Fernando y Luscinda, tan cervantinas como la de los molinos, quedan reducidas a un genial hallazgo narrativo de don Domingo Abeja:

Mas como acertaran a ver por allí a cierto sujeto llamado Cardenio y una señora Dorotea, después de saludarles cortésmente, entablaron plática con ellos y les contaron con brevedad la causa que allf los había traído, con la extrañeza de la locura de Don Quijote ${ }^{10}$.

No hay reina Madásima, no hay Cardenio loco que surta de modelo real la locura de don Quijote, no hay virginidad perdida de Dorotea -reducida a simple princesa Micomicona-, ni falso don Fernando, ni Luscinda. Fiel a sí mismo, nuestro editor elimina esmerada y concienzudamente todo rastro de sus peripecias y de las que alrededor suyo acaecen. Como era de esperar, la siguiente desaparición es la de «El curioso impertinente» ${ }^{11}$. A la de la novelita, sigue la de toda la anagnórisis en cadena que tiene lugar en la venta de Juan Palomeque el Zurdo. Si nunca llegan allí don Fernando y Luscinda, tampoco lo hacen el capitán cautivo Ruy Pérez de Viedma y Zoraida María,

${ }^{10}$ ABEJA, Domingo: op. cit., pág. 262.

${ }^{11}$ La supresión de la novelita obliga al censor a prescindir de todas las referencias que a ella se hacen a lo largo de la primera y segunda parte. Entre ellas se encuentra una de las tres ocasiones en que Miguel de Cervantes Saavedra aparece como personaje en su novela, como huésped de la venta de Juan Palomeque y autor de «Rinconete y Cortadillo» y de «El curioso impertinente» (Cfr. Don Quijote, I, XXXII y XLVII). Lo mismo sucede con la historia del cautivo, también suprimida, y con ella la mención a «un soldado español llamado tal de Saavedra” (Don Quijote, I, XL). 
ni don Juan Pérez de Viedma, oidor de la Audiencia de México, y su hija doña Clara, ni en pos de ellos llega el enamorado don Luis, seguido por los criados de su padre. En la segunda parte, los personajes censurados de entre este grupo de episodios son menos: los hijos de don Diego de la Llana, que Sancho encuentra travestidos durante la ronda nocturna, la engañada Claudia Jerónima y la hija de Ricote, Ana Félix.

El número de episodios cómicos considerados inmorales es notablemente menor. Sólo cuatro se excluyen por completo, dos pertenecientes al palacio de los duques y dos a la venta. Los primeros son el de Altisidora y el de doña Rodríguez, aunque su personaje se mantiene. Los otros dos tienen como partícipe a Maritomes, en su fallido negocio con el harriero y en la invención que, con la hija del ventero, pone en práctica para dejar a don Quijote colgando de una ventana hasta el amanecer. El resto son fragmentos o pasajes breves de diversa índole: la menstruación de Belerma, las relaciones clandestinas de la infanta Antonomasia y don Clavijo, las urgencias de Sancho en la aventura de los batanes y su juicio en la falsa violación.

Juramentos, maldiciones y expresiones malsonantes a los oídos del editor siguen el mismo camino. Léase: «maldito», «oxte, puto», «hideputa», «sesenta mil satanases», «en pelota», «que el diablo me lleve» o, simplemente, «juro». La nómina sería innecesariamente tediosa y sólo quisiera llamar la atención sobre dos lugares, como muestra de la tiranía que la moralidad ejerce incluso sobre la misma erudición. En el capítulo XXV de la segunda parte, Sancho hace uso de un obvio eufemismo: «Voto a Rus». Don Domingo Abeja mantiene la expresión y la nota que la explica no tiene desperdicio: «Este juramento sería tal vez a Rus, el señor de un castillo que hubo en la Mancha» ${ }^{12}$. Ocho capítulos después, durante «la sabrosa plática que la duquesa y sus doncellas pasaron con Sancho Panza», doña Rodríguez hace mención de un conocido romance sobre la muerte del rey godo don Rodrigo:

Ya me comen, ya me comen, por do más pecado había.

El segundo verso desaparece en el texto de la edición y lo mismo ocurre en la nota que, a pie de página, reproduce el romance completo, a pesar de romper con ello la alternancia de rima ${ }^{13}$.

No ha de extrañar esta omisión, porque el censor se ensaña con los poemas incluidos en el Quijote y no deja títere co cabeza. De todo el cancionero que, de algún modo, es la novela de Cervantes, sólo quedan dos poemas y ambos pertenecientes a la segunda parte: la glosa de don Lorenzo, hijo del caballero del Verde Gabán, y la profecía en que Merlín anuncia los tres mil trescientos azotes necesarios para desencantar a

${ }^{12}$ ABEJA, Domingo: op, cit.; tomo II, pág. 283.

${ }^{13}$ En general todo el aparato de notas adolece de un innecesario alarde erudito común a las ediciones del siglo XIX, tan útiles como excesivas. A subrayar la nota que, en el capítulo LVI de la segunda parte, se trae a raíz de don Diego Matamoros: «Muy oportuno es el apellido de 'Matamoros' que se da a Santiago por la protección que dispensó a los españoles apareciéndose visiblemente muchas veces» (ABEJA, D.: op. cit.; $t$. III; pág. 247). Se sigue un recuento detallado de las veinticinco apariciones de Santiago, desde Recaredo hasta Pedro de Alvarado. 
Dulcinea. Ni un sólo poema en toda la primera parte, desde los elogios preliminares hasta el «Hoc scripserunt» de los académicos de Argamasilla, del que, como de muchos de los cronicones al uso, queda la noticia más no la transcripción ${ }^{14}$.

Hay que decir en honor del señor Abeja que su trabajo es intachable, pues entre tanto recorte cabría esperar algún descuido y sólo tres le son imputables: la aparición repentina de «la asturiana», sin que previamente se mencionará para nada a Maritornes; la vihuela que don Quijote encuentra sin más en sus aposentos y que originalmente había pedido para rondar a Altisidora; y la defensa que Cervantes hace de los episodios intercalados en el capítulo XLIV de la segunda parte, que el editor mantiene después de haber prescindido de todos y cada uno de ellos en la primera.

En lo referente a Dulcinea don Domingo Abeja hiló menos fino, pues una y otra vez le escamotea su amor a don Quijote. Dulcinea es la razón de ser de don Quijote y, sin embargo, aquí se debilita su imagen o incluso llega a desaparecer en tres momentos claves de su acción heroica: la penitencia en Sierra Morena, la bajada a la cueva de Montesinos y los proyectos de vida pastoril. Las otras omisiones coinciden en adelgazar la belleza de la dama o la intensidad y el modo del amor de su caballero, hasta casi hacer de él, como ya hiciera Alonso Fernández de Avellaneda, el Caballero Desamorado.

¿Qué hay de común entre todos los episodios de los que acabamos de hacer nómina? El amor, el amor en sus más diversas formas. Excepción hecha de pocos lances cómicos y de expresiones malsonantes, el resto de los lugares y personajes censurados se mueven arrebatados por un remolino erótico. Marcela, Cardenio, Maritornes, Zoraida, Altisidora, Anselmo, Tosilos o la misma Dulcinea representan diferentes caras del amor. Lo que, consciente o inconscientemente, pretendió don Domingo Abeja fue reescribir un Don Quijote de la Mancha sin amor. Cabe ahora preguntarse por qué.

Publicar una obra -dice Escarpit- es acabarla totalmente mediante su abandono a los demás. Para que una obra exista verdaderamente como fenómeno autónomo y libre, como criatura, es preciso que se desprenda de su creador y siga sola su camino entre los hombres ${ }^{15}$.

Cervantes corrió ese riesgo, pero sin sospechar que habían de atentar contra la integridad física de su obra. Don Domingo Abeja, como lector del Quijote, se encuentra en un plano diametralmente opuesto al del lector implícito en la obra. Entre el Quijote

${ }^{14} \mathrm{El}$ Quijote todo y, en especial, el pasaje de los manuscritos, «escritos con letras góticas, pero en versos castellanos», encontrados en una caja de plomo por un antiguo médico son una burla de la afición que sus contemporáneos tenían a descubrir reliquias y desempolvar crónicas de dudosa patemidad. Cervantes conoció y juzgó en la tan traída y llevada polémica de los plomos de Granada y el cronicón de Dextro. La primera parte del Quijote se publica en 1605 y el pergamino de la torre Turpiana data de 1588 , los libros plúmbeos de Granada de 1595 y el padre Jerónimo Román de la Higuera dio a conocer sus falsas crónicas en 1596. De ahí en adelante, la polémica (Cfr. GODOY ALCANTARA, José: Historia de losfalsos cronicones. Madrid, Alatar, 1981). No poco tuvieron que influir en Cervantes todas estas historias para montar su entarimado de autores árabes y mentirosos, moriscos aljamiados que traducen a sus anchas, segundos autores cristianos que cuestionan la autenticidad de sus fuentes, manuscritos encontrados y apócrifos. En breve, habrá mejor lugar para contarlo.

${ }^{15}$ Op. cit., pág. 64. 
de Cervantes y su editor de 1896 se produce, en grado extremo, lo que Wolfgang Iser llama «asimetría de texto y lecton» ${ }^{16}$. La consecuencia de tal asimetría acabamos de verla, puesto que el señor Abeja no era un simple lector. Era un editor que usó y abusó de su condición para imponer su particular criterio de moralidad, no ya en su propia lectura, sino en las ajenas, rompiendo la regla principal en cualquier acto de lectura: el texto como realidad dada e inalterable.

ElQuijote que recibieron los lectores de esta edición era un texto manipulado, una obra distinta que presupone un nuevo lector, adecuado al texto. El encabezamiento de la obra nos da la pista para caracterizarlo: «Edición... arreglada para toda clase de persona y en especial para uso de los colegios». Basta bajar la vista para encontrar a los responsables materiales de la edición: Tipografía y Librería Salesianas. Sacerdotes y educadores. A sus necesidades, a su interpretación del mundo y a su moralidad responde la obra. Como responsables de la educación de jóvenes, optaron por un Quijote sin amor, esto es, sin peligro. Como representantes de la institución religiosa, descargaron la obra de una profundidad que, es posible, ellos mismos tampoco comprendieran. En ambos casos, libraron a sus lectores -jóvenes u hombres de la Restauración- de la responsabilidad de interpretar.

Comprender es interpretar -escribe Susan Sontag-. E interpretar es restaurar el fenómeno con intención de encontrar su equivalente. Así pues, la interpretación no es, como la mayoría de las personas presumen, un valor absoluto, un gesto de la mente situado en algún dominio intemporal de las capacidades humanas. La interpretación debe ser valorada dentro de una concepción de la conciencia humana ${ }^{17}$.

Don Domingo Abeja nunca quiso comprender el Quijote, se limitó a tachar, es decir, a imponer, con los mecanismos que su posición de editor le facilitaba, su canon de moralidad, el mismo de la Restauración, y hacerlo prevalecer a través del sistema educativo. Para ello no tuvo inconveniente en tomar bando con los «presuntuosos y malandrines historiadores», haciendo caso omiso a la advertencia del primer y verdadero autor de la obra:

¡Tate, tate, folloncicos!

De ninguno sea tocada;

porque esta empresa, buen rey, para mí estaba guardada.

${ }^{16}$ Cfr. ISER, Wolfgang: El acto de leer, Madrid, Taurus, 1987, pág. 255.

${ }^{17}$ SONTAG, Susan: Contra la interpretación, Barcelona, Seix Barral, 1967, pág. 16. 